\title{
Awareness, knowledge and the factors that affect the use of folic acid among pregnant and non-pregnant women in the repro- ductive age in a selected area in Colombo district, Sri Lanka
}

\author{
R Pathiraja ${ }^{\mathrm{a}}$, S Prathapan ${ }^{\mathrm{b}}$
}

\begin{abstract}
Background: The prevalence of neural tube defects in Sri Lanka is estimated to be 1.21 per 1000 births. According to the WHO, programs to increase folic acid (FA) consumption among women of reproductive age may benefit countries where the NTD rate is higher than $0.6 / 1,000$ live births. Food fortification is an effective method but there is still no mandatory fortification policy in Sri Lanka. Therefore, improving knowledge and voluntary use of FA remains a high priority. The study aimed to determine the awareness and knowledge on FA among pregnant and non pregnant women.

Methods: A comparative cross-sectional study was conducted among 400 pregnant and 400 non-pregnant women aged 18-45 years from Colombo District in Sri Lanka. Data were collected using an anonymous, standardized, intervieweradministered questionnaire, which included questions about socio-demographic data, obstetric history, FA knowledge and use.

Results: FA awareness and knowledge on its pre-conceptional use were significantly low among non-pregnant women younger than 25 years $(\mathrm{OR}=0.120,95 \% \mathrm{Cl}=0.068-0.211, \mathrm{p}=0.000 ; \mathrm{OR}=0.153,95 \% \mathrm{Cl}=0.090-0.262, \mathrm{p}=0.000$ ).

Pregnant women with knowledge that FA prevents birth defects were significantly more likely to take FA during pregnancy $(\mathrm{OR}=10.760,95 \% \mathrm{Cl}=1.244-93.068, \mathrm{p}=0.007)$ and the pre-conceptional period (OR=1.807, 95\% $\mathrm{Cl}=1.172-2.786, \mathrm{p}=0.007)$.

Women who received information from field clinics were significantly more likely to have FA awareness (OR $=4.779,95 \%$ $\mathrm{Cl}=0.913-25.021, \mathrm{p}=0.042)$, knowledge on pre-conceptional use of $\mathrm{FA}(\mathrm{OR}=2.972,95 \% \mathrm{Cl}=1.179-7.491, \mathrm{p}=0.016)$ and took FA during pregnancy $(\mathrm{OR}=39.773,95 \% \mathrm{Cl}=4.542-348.271, \mathrm{p}=0.000)$. Those who received information from home visits were significantly more likely to have knowledge on the role of $\mathrm{FA}$ in preventing birth defects $(\mathrm{OR}=1.958,95 \% \mathrm{Cl}=1.133-3.384$, $\mathrm{p}=0.015)$, took FA during their pregnancy $(\mathrm{OR}=15.102,95 \% \mathrm{Cl}=1.743-130.841, \mathrm{p}=0.001)$ and in the pre-conceptional period $(\mathrm{OR}=2.117,95 \% \mathrm{Cl}=1.316-3.405, \mathrm{p}=0.002)$. Women who got information through media were also significantly more likely to have knowledge on the role of $\mathrm{FA}$ in preventing birth defects. ( $\mathrm{OR}=2.487,95 \% \mathrm{Cl}=1.006-6.149, \mathrm{p}=0.042)$.

Conclusions: Health education campaigns have to be specifically targeted for younger women from ethnic minorities and from low household income families. Field clinics and home visits from public health midwives have been a significant sources of information and media campaigns can be an effective means of promoting health education regarding use of preconceptional folic acid.
\end{abstract}

Key words: folic acid, pregnant women, awareness, reproductive age, neural tube defects

Sri Lanka Journal of Obstetrics and Gynaecology 2020; 42: 105-114

DOI: http://doi.org/10.4038/sljog.v42i3.7956

a Professor of Obstetrics and Gynaecology, Faculty of Medical Sciences, University of Sri Jayewardenepura, Sri Lanka.

b Consultant Community Physician, Faculty of Medical Sciences, University of Sri Jayewardenepura, Sri Lanka

Correspondence: RP, e-mail: ramya_pathiraja@sjp.ac.lk

iD https://orcid.org/0000-0002-3673-4466

Received $10^{\text {th }}$ July 2020

Received version accepted $23^{\text {rd }}$ September 2020

This is an open-access article distributed under the terms of the Creative Commons Attribution 4.0 International License, which permits unrestricted use, distribution and reproduction in any medium provided the original author and source are credited. 


\section{Introduction}

Each year 300,000 to 400,000 infants worldwide are born with neural tube defects (NTDs) ${ }^{1}$ which accounts for an estimated 41,000 deaths and 2.3 million disabilityadjusted life years ${ }^{2}$. The reported prevalence of NTD in the South-East Asian region ranges from 1.9-66.2 per 10,000 births, with a median of 15.8 per 10,000 births $^{3}$. The prevalence of NTD in Sri Lanka is estimated to be 1.21 per 1000 births $^{4}$. The risk of recurrence of NTD is reported as $2-3 \%$.

Folic acid (FA) is essential for cell proliferation and cell vitality ${ }^{5}$. It plays an important role in cell growth and development, particularly central nervous system development and tissue formation ${ }^{6-7}$ and therefore it is particularly important during pregnancy and infantile period when there is rapid cell division and growth ${ }^{5}$. Daily consumption of supplement containing FA before pregnancy has shown to have a protective effect for both in the first occurrence of $\mathrm{NTDs}^{8}$ and the recurrence $^{9}$. FA may also provide protection for other selected birth defects such as cardiovascular defects, limb defects, cleft lip and cleft palate, urinary tract anomalies and congenital hydrocephalus ${ }^{10-11}$.

The World Health Organization recommends intake of $400 \mu \mathrm{g}$ of folic acid pre conceptionally until 12 weeks of pregnancy ${ }^{12}$. For women with a history of delivery of a baby with a NTD, diabetes, or receiving anticonvulsant treatment, the recommended daily dose is $5 \mathrm{mg}$ of folic acid in addition to dietary advice to increase food FA intake ${ }^{12-13}$. Despite this recommendation, supplementation is still underutilized by non-pregnant women ${ }^{14}$.

Food fortification has been found to be a most effective method of improving folate intake ${ }^{15-17}$ and prevention of NTDs ${ }^{18-20}$. As the majority of pregnancies are unplanned, fortification of staple foods with folic acid is being mandated in some countries with a $27-46 \%$ reduction of $\mathrm{NTD}^{21}$. As there is still no mandatory fortification policy in Sri Lanka, improvement in knowledge and voluntary use of folic acid remains a high priority.

It would seem reasonable to implement both interventions, especially in countries with a high prevalence of birth defects ${ }^{22}$.

Majority of Sri Lankan women have poor knowledge on proper nutrition during pregnancy and lactation ${ }^{23}$ and there are no published reports in Sri Lanka regarding the prevalence of pre-conceptional FA intake. Little is known about what motivates young women to become informed about the use of FA supplementation.

This study is designed to determine the level of FA supplement use among pregnant women and also in non-pregnant women who may be at risk of an unintended or unplanned pregnancy and to determine the demography, health beliefs, and health behaviour characteristics of women that could potentially affect their regular intake of FA.

\section{Materials and methods}

This was a cross-sectional observational study. Study population were pregnant and non-pregnant women of aged 18-45 years. At 95\% confidence interval and at an expected proportion of 50\%, 384 women were to be recruited. With $10 \%$ of non-response rate, the sample size was increased to 400. Data were collected from 400 pregnant women who attended antenatal clinic at Dehiwala MOH (Medical Officer of Health) area and another 400 non-pregnant women were chosen equally from non-pregnant women admitted to the Gynaecology ward in a selected Teaching Hospital in Sri Lanka and from non-pregnant women from a garment factory in the sub urban area of Sri Lanka.

Before commencing data collection, the research officer was provided with broad knowledge on the objectives, and trained on how to conduct a standardized interview. Data were collected using an anonymous, standardized, interviewer-administered questionnaire by an interviewer. The questionnaire included questions about socio demographic data, obstetric history, folic acid knowledge and its use.

Folic acid awareness was defined as having ever heard of folic acid. Knowledge about folic acid was defined as knowing that folic acid prevents NTDs and knowing the correct time to take folic acid. Folic acid use was defined as a self-report of ever having taken folic acid supplements or multivitamins containing folic acid at least once a day during pregnancy.

The questionnaire was translated into two local languages - Sinhalese and Tamil. These were translated back to English to confirm the accuracy of the translation. The translated versions of the questionnaires were pre-tested among two groups of ten pregnant 
women and ten non-pregnant women residing outside the study setting areas. Questions were modified as necessary. Women were provided with an information sheet to receive an idea about the study and informed written consent was obtained prior to recruitment to the study, with knowledge that they have the right to refuse to participate. Identities of the participating women were kept confidential. No identifying information was obtained on the survey so that the anonymity of participating women was protected. Women who agreed to participate were interviewed regardless of whether it was their first or follow-up visit. The interview was conducted by the trained research officer, who followed the questions structure strictly with agreed-upon alternative explanations.

The interviewer visited the antenatal clinics and the Gynaecology wards in the teaching hospital. Pregnant women were interviewed while they were awaiting their antenatal clinics, non-pregnant women from those at the Gynaecological wards at Colombo South Teaching Hospital and those employed at a garment factory, were interviewed ensuring that they were in a separate area from the other participants of the study to maintain privacy and confidentiality.

The Statistical Package for Social Sciences was used for the statistical analysis of the data. Qualitative variables were expressed as frequencies and percentages. Quantitative continuous variables were expressed as mean and standard deviation (SD). A multivariate logistic regression analysis was conducted to examine the association of awareness and intake of folic acid supplements. The criteria for statistical significance was set at $5 \%$.

\section{Results}

In the study population, $67.8 \%$ of pregnant women and $65.5 \%$ of non-pregnant women were between 25-34 years of age. $51.5 \%$ of the study population were in their first pregnancy and 3.3\% of pregnant women were at $0-12$ weeks of gestation at the time of recruitment to the study. Folic acid was used by $98.4 \%$ of pregnant women during their pregnancy, while $1.5 \%$ did not use due to lack of awareness. Among those who used folic acid during pregnancy, only $44.9 \%$ started prior to pregnancy.

In the study population, 92.2\% have used folic acid during their previous pregnancies. Almost all women who used folic acid in their previous pregnancies continued to use folic acid in their current pregnancy as well. In the non-pregnant population, 94.3\% were heard about folic acid and was aware that folic acid has to be used prior to conception and $16 \%$ of them have not heard about folic acid. Awareness was highest among women who were educated (91.5\%) among housewives (95.9\%) and who were employed (81.8\%).

Table 1. Sociodemographic factors of the pregnant and non-pregnant women

\begin{tabular}{|c|c|c|c|c|}
\hline & \multicolumn{2}{|c|}{ Non Pregnant women } & \multicolumn{2}{|c|}{ Pregnant women } \\
\hline & Frequency & Percentage & Frequency & Percentage \\
\hline \multicolumn{5}{|l|}{ Age (years) } \\
\hline $15-24$ & 84 & 21.0 & 89 & 22.3 \\
\hline $25-34$ & 262 & 65.5 & 271 & 67.8 \\
\hline $35-44$ & 54 & 13.5 & 40 & 10.0 \\
\hline \multicolumn{5}{|l|}{ Ethnicity } \\
\hline Sinhala & 362 & 90.5 & 342 & 85.5 \\
\hline Tamil & 29 & 7.3 & 30 & 7.5 \\
\hline Muslim & 9 & 2.3 & 28 & 7.0 \\
\hline
\end{tabular}




\begin{tabular}{|c|c|c|c|c|}
\hline & \multicolumn{2}{|c|}{ Non-pregnant women } & \multicolumn{2}{|c|}{ Pregnant women } \\
\hline & Frequency & Percentage & Frequency & Percentage \\
\hline \multicolumn{5}{|l|}{ Area of living } \\
\hline Urban & 328 & 82.0 & 395 & 98.8 \\
\hline Rural & 72 & 18.0 & 5 & 1.3 \\
\hline \multicolumn{5}{|l|}{ Marital status } \\
\hline Single & 102 & 25.5 & 00 & 0.0 \\
\hline Married & 289 & 72.3 & 400 & 100 \\
\hline Divorced & 9 & 2.3 & 00 & 0.0 \\
\hline \multicolumn{5}{|l|}{ Occupation } \\
\hline Employed & 4 & 1.0 & 84 & 21.0 \\
\hline Health Sector & 333 & 83.2 & 9 & 10.7 \\
\hline Other & 0 & 0 & 75 & 99.3 \\
\hline Self employed & 14 & 3.5 & 1 & .3 \\
\hline House wife & 49 & 12.3 & 315 & 78.8 \\
\hline \multicolumn{5}{|l|}{ Education level } \\
\hline Not attended school & 3 & 0.8 & 2 & 0.5 \\
\hline Upto grade 5 & 9 & 2.3 & 4 & 1.0 \\
\hline Upto grade 10 & 58 & 14.5 & 45 & 11.3 \\
\hline Passed O/L & 223 & 55.9 & 197 & 49.3 \\
\hline Passed A/L & 106 & 26.6 & 138 & 34.5 \\
\hline Graduate & 0 & 0 & 14 & 3.5 \\
\hline \multicolumn{5}{|l|}{ Family income } \\
\hline less than 5000 & 10 & 2.5 & 2 & 0.5 \\
\hline 5000-14999 & 132 & 33.0 & 14 & 3.5 \\
\hline 15000-24999 & 185 & 46.3 & 201 & 50.3 \\
\hline 25000-34999 & 65 & 16.3 & 159 & 39.8 \\
\hline 35000-44999 & 6 & 1.5 & 13 & 3.3 \\
\hline 45000 or more & 2 & 0.5 & 11 & 2.8 \\
\hline
\end{tabular}


Table 2. Folic acid awareness among non-pregnant women and socio-demographic factors

\begin{tabular}{|c|c|c|c|c|}
\hline & \multicolumn{4}{|c|}{ Folic acid awareness among non-pregnant women } \\
\hline & Yes & & No & \\
\hline & $\mathbf{n}$ & $(\%)$ & $\mathbf{n}$ & $(\%)$ \\
\hline \multicolumn{5}{|l|}{ Age } \\
\hline $15-24$ & 44 & 55.0 & 36 & 45.0 \\
\hline $25-34$ & 231 & 88.2 & 31 & 11.8 \\
\hline $35-44$ & 54 & 100.0 & 0 & 0 \\
\hline \multicolumn{5}{|l|}{ Ethnicity } \\
\hline Sinhala & 306 & 85.5 & 52 & 14.4 \\
\hline Tamil & 15 & 51.7 & 14 & 48.3 \\
\hline Muslim & 8 & 88.9 & 1 & 11.1 \\
\hline \multicolumn{5}{|l|}{ Area of living } \\
\hline Urban & 272 & 84.0 & 52 & 16.0 \\
\hline Rural & 57 & 79.2 & 15 & 20.8 \\
\hline \multicolumn{5}{|l|}{ Marital status } \\
\hline Unmarried & 47 & 47.0 & 53 & 53.0 \\
\hline Married & 273 & 95.1 & 14 & 4.9 \\
\hline Divorced & 9 & 100.0 & 0 & 0 \\
\hline \multicolumn{5}{|l|}{ Level of education } \\
\hline Not attended school & 2 & 66.7 & 1 & 33.3 \\
\hline Up to grade 5 & 1 & 16.7 & 5 & 83.3 \\
\hline Up to grade 10 & 47 & 82.5 & 10 & 17.5 \\
\hline Passed O/L & 182 & 81.6 & 41 & 18.4 \\
\hline Passed A/L & 97 & 91.5 & 9 & 8.5 \\
\hline Graduate & 0 & 0 & 0 & 0 \\
\hline \multicolumn{5}{|l|}{ Occupation } \\
\hline Employed & 278 & 81.8 & 62 & 18.2 \\
\hline Health Sector & 3 & 75.0 & 1 & 25.0 \\
\hline Other & 275 & 81.8 & 61 & 18.2 \\
\hline Self-employed & 7 & 63.6 & 4 & 36.4 \\
\hline Housewife & 47 & 95.9 & 2 & 4.1 \\
\hline \multicolumn{5}{|l|}{ Family income } \\
\hline Less than 5000 & 6 & 60.0 & 4 & 40.0 \\
\hline 5000-14999 & 92 & 71.9 & 36 & 28.1 \\
\hline $15000-24999$ & 167 & 90.3 & 18 & 9.7 \\
\hline 25000-34999 & 57 & 87.7 & 8 & 12.3 \\
\hline $35000-44999$ & 5 & 83.3 & 1 & 16.7 \\
\hline 45000 or more & 2 & 100.0 & 0 & 0 \\
\hline
\end{tabular}


Among the women who had heard about FA, only 221 (66.4\%) women had consumed FA during their past pregnancies, whereas $6(1.5 \%)$ have not consumed it in the present pregnancy. When comparing the previous pregnancy with the current pregnancy 2 (0.5\%) pregnant women have not received FA for both pregnancies, with reasons that FA was not needed during pregnancy.

Table 3. Usage of folic acid during past pregnancies

\begin{tabular}{|c|c|c|}
\hline & Frequency $(n=333)$ & Percentage \\
\hline \multicolumn{3}{|c|}{ Folic acid intake during past pregnancy } \\
\hline Yes & 221 & 66.4 \\
\hline No & 112 & 33.6 \\
\hline \multicolumn{3}{|l|}{ Reasons for not taking FA } \\
\hline Not needed & 104 & 92.9 \\
\hline Not known & 7 & 6.3 \\
\hline Had side effects & 1 & 0.9 \\
\hline \multicolumn{3}{|c|}{ Congenital abnormalities in past pregnancies } \\
\hline Yes & 13 & 3.9 \\
\hline Neural tube defect & 06 & 1.8 \\
\hline Structural heart defects & 02 & 0.6 \\
\hline Bone defects & 05 & 1.5 \\
\hline No & 319 & 96.1 \\
\hline
\end{tabular}

It was shown that 13 (3.9\%) women who has not taken FA in the past pregnancies, all had congenital abnormal babies in the past. However, only $45 \%$ of pregnant women had consumed FA before conception in the present pregnancy. $88 \%$ of the women have come to know of FA at the clinic and another $28 \%$ had incorrect conception on FA.

Table 4. Intake of folic acid among folic acid users

\begin{tabular}{|lll|}
\hline & Frequency (n=333) & Percentage \\
\cline { 2 - 3 } First started on FA & 177 & 44.9 \\
Before conception & & \\
After conception & 199 & 50.5 \\
$<12$ weeks & 05 & 1.3 \\
12 - 28 weeks & & \\
Duration of intake* & 02 & 0.5 \\
$<1$ month & 22 & 5.6 \\
$1-3$ months & 95 & 24.2 \\
3 - 4 months & 274 & 69.7 \\
$>5$ months & & \\
Frequency of intake & 1 & 0.3 \\
On and off & 393 & 99.7 \\
Once daily & & \\
\end{tabular}


On multivariate analysis, awareness of FA from the PHM (Public health midwife) home visits, awareness from the clinics and the knowledge that it prevents birth defects had significantly higher odds among women consuming FA than women not consuming FA.

Table 5. Risk of intake of folic acid among pregnant women

\begin{tabular}{|llll|}
\hline & \multicolumn{2}{c}{ Taking FA } & Adjusted OR (95\% CI) \\
\hline Yes (\%) & No (\%) & \\
\hline Known about FA from home visits & 296 & 01 & $15.10(1.7-130.8)$ \\
Prevent birth defects & 350 & 01 & $39.7(4.5-348.0)$ \\
& 269 & 01 & $10.8(1.2-93.8)$ \\
\hline
\end{tabular}

Awareness of pre-conceptional folic acid use were higher (79.8\%) among women both who were intended to become pregnant and also who never intended to be pregnant $(81.1 \%)$ in near future. Home visits by family health workers and the field clinics were the main source of information about the knowledge and the benefits of the use of folic acid. Other source of information includes visits to general practitioner, and from the media.

\section{Discussion}

As medical and public health professionals we have an obligation to take measures to prevent certain diseases that are readily preventable. With regard to folic acidpreventable birth defects, that obligation has not yet been met in Sri Lanka. While some progress is being made to increase folic acid consumption among certain groups of women, much more work remains to be done.

There are no published data on FA awareness and use among women of childbearing age in Sri Lanka. Awareness and the knowledge on pre-conceptional FA use were high in our study compare to similar studies carried out in Asia ${ }^{24-26}$ and United States of America (USA) $^{27}$. Although, about $98.5 \%$ of pregnant women used FA, they haven't taken FA during the critical period of time crucial for preventing NTDs. Only $44.9 \%$ had been on pre-conceptional FA and little more than half started taking FA during the first trimester of pregnancy. This may be due to the fact that the first pregnancy of many women of childbearing age is unplanned.
Clear differences were observed among different subgroups of non-pregnant women. FA awareness was least among non-pregnant women aged compatible with other studies reported ${ }^{26-30}$. As there is also an increase rate of unplanned pregnancies in these age group $^{31}$ health care professionals should educate all men and women of reproductive age regarding the benefits of pre-conceptional FA consumption.

Ethnicity is one of the factors associated with low use of FA supplements ${ }^{32}$ and we also noted a significant difference in the knowledge in ethnic minority even though their representation in our study was small in number. Parity was found to have significant influence on the continuation of folic acid ${ }^{29}$ in subsequent pregnancies. Level of education has been associated with an increase awareness, knowledge and use of $\mathrm{FA}^{26,27,33-37}$ and significantly high prevalence of daily folic acid intake among some socio demographic groups was encouraging and suggests that there is a need to intensify FA education programs with a focus toward women with low socio economic status.

Main source of information on FA use and its benefits among both pregnant and non-pregnant women in our study were mainly from the field health care workers compared to other countries where the Obstetrician and Gynaecologist and a general practitioner, play a major role ${ }^{38-41}$.

Limitations noted in our study included an overrepresentation of women from urban areas and an under-representation of women from ethnic minorities ${ }^{42}$. 
The rates of awareness and knowledge of FA reported from the study likely overestimates the rates from the rural population and ethnic minorities. Furthermore, all pregnant women included in the study were married. Therefore, the population does not represent absolute number of unplanned pregnancies and likely overestimates the rates of pre-conceptional folic acid supplementation.

\section{Conclusions and recommendations}

Folic acid intake during pregnancy was high among pregnant women in this study with only a minority started taking FA pre-conceptionally. Awareness and knowledge on its pre-conceptional use was high among both pregnant and non-pregnant women. Women who had knowledge on the role of folic acid in preventing birth defects were significantly more likely to take folic acid during pregnancy and the pre-conceptional period. Field clinics and home visits from public health midwives have been significant sources of information regarding folic acid for pregnant as well as nonpregnant women.

Knowledge gap between the awareness and the correct timing of FA consumption need to be addressed by means of developing necessary basic health policies in order to achieve primary protection by taking into account the socioeconomic status, educational level of women, knowledge regarding folic acid and neural tube defects, and rates of unplanned pregnancies. As essential amounts of folic acid cannot be achieved by diet alone, daily folic acid supplementation should be given to women during the peri-conceptional period. Efforts also needed to take to promote the optimal use of folic acid supplements.

While a major role is played by field healthcare workers in promoting health education, there is room to improve in the part of promoting health education by further strengthening of the role played by field healthcare workers, through doctors providing first contact care at hospitals, general practitioners, and mass media campaigns, especially targeting non-pregnant women.

\section{Author Declarations}

Competing interests: The authors declare that they have no competing interests.

Financial disclosure: The study was self-financed.
Authors' contributions: RP conceived and designed the study, extracted data, interpreted the data, compiled and revised the manuscript. SP conducted statistical analysis, interpreted the data, and revised the manuscript. All authors have read and approved the final version.

Ethics approval and consent to participate: This study obtained ethical clearance from Ethical Review Committee, Faculty of Medical Sciences, University of Sri Jayewardenepura (Reference number: 38/15). Informed written consent was taken from all the participants prior to data collection.

Availability of data and materials: The datasets generated and/or analysed during the current study are available from the corresponding author on reasonable request.

\section{References}

1. Godfrey P, Oakley Jr. Centers for Disease Control and Prevention, Atlanta, GA, USA Bulletin of the World Health Organization. 1998; 76 (SuppI 2): 116-117.

2. The Global Burden of Disease [Internet]. [[13 September 2009, date last accessed]]. update. 2004.

3. Zaganjor I, Sekkarie A, Tsang BL, Williams J, Razzaghi H, Mulinare J, et al. Describing the Prevalence of Neural Tube Defects Worldwide: A Systematic Literature Review. PLoS ONE. 2016; 11(4): e0151586

4. Souza JP, Gülmezoglu AM, Carroli G, Lumbiganon P, Qureshi Z, WHOMCS Research Group. The World Health Organization multicountry survey on maternal and newborn health: study protocol BMC Health Services Research 2011; 11: 28.

5. Akkoca AN, Kurt RK, Karapinar OS, Ozler S, Ozer C. Folic Acid Use and Knowledge among Women in Reproductive Age. Turkish Journal of Family Medicine and Primary Care (TJFMPC). 2014; 8(2): 35-38.

6. American Academy of Pediatrics, Policy statement. Folic acid for the prevention of neural tube defects. Pediatrics September 1993; 92(3): 493-4. 
7. Friel JK, Frecker M, Frase FC. Nutritional patterns of mothers of children with neural tube defect in Newfoundland. Am J Med Genet 1995; 55: 195-9.

8. Czeizel AE, Dudas I. Prevention of the first occurrence of neural-tube defects by periconceptional vitamin supplementation. N Engl J Med 1992; 327: 1832-5.

9. Wald N, Sneddon J. Prevention of neural tube defects: Results of the Medical Research Council Vitamin Study. Lancet 1991; 338: 131-7.

10. Coppede F, et al. Association of maternal polymorphisms in folate metabolizing genes with chromosome damage and risk of Down syndrome offspring. Neurosci Lett. 2009; 449(1): 15-9.

11. Wilcox AJ, et al. Folic acid supplements and risk of facial clefts: national population based casecontrol study. BMJ 2007; 334 (7591): 464.

12. Periconceptional daily folic acid (400 $\mu \mathrm{g})$ supplementation for prevention of neural tube defects. Department of Nutrition for Health and Development, Evidence and Programme Guidance Unit World Health Organization 2006.

13. Bale JR, Stoll BJ, Lucas AO, editors. Reducing birth defects: meeting the challenge in the developing world. National Academies Press; Washington: 2003.

14. CDC Recommendations for the use of folic acid in prevention of spina bifida and anencephaly MMWR 2002; 51(RR13); 1-3.

15. Krischer J. Knowledge about folic acid and the prevention of neural tube defects in two general practice populations. Br J Gen Pract. 1997; 47: 231-2.

16. Jessa F, Hampshire AJ. Use of folic acid by pregnant British Pakistani women: a qualitative pilot study. Health Educ J. 1999; 58: 139-45.

17. Brough L, Rees GA, Crawford MA, et al. Social and ethnic differences in folic acid use preconception and during early pregnancy in the UK: effect on maternal folate status. J Hum Nutr Diet. 2009; 22: 100-7.

18. Botto LD, Lisi A, Robert-Gnansia E, Erickson JD, Vollset SE, Mastroiacovo P, et al. International retrospective cohort study of neural tube defects in relation to folic acid recommendations: are the recommendations working? BMJ. 2005; 330: 571-3.
19. De Wals P, Tairou F, Van Allen MI, Uh SH, Lowry $\mathrm{RB}$, Dibbald B, et al. Reduction in neural-tube defects after folic acid fortification in Canada. New England Journal of Medicine 2007; 357(2): 135-42.

20. Berry RJ, Bailey L, Mulinare J, Bower C. Folic Acid Working Group. Fortification of flour with folic acid. Food Nutrition Bulletin. 2010; 31

21. Dunlup B, et al, Folic acid and human reproduction - ten important issues for clinician, J Exp Clin Assist Reprod 2011; 8: 2.

22. De Wals P, et al. Reduction in neural-tube defects after folic acid fortification in Canada. N Engl J Med. 2007; 357(2): 135-42.

23. Kumarapeli V, Athauda T. A comparison of the dietary pattern of adolescent school girls in two defined urban and rural settings, Journal of the Community Physicians of Sri Lanka 2004; 9: 13-17.

24. Gupta, P. Awareness regarding use of folic acid for prevention of congenital neural tube defects. Natl Med J India. 2000.

25. Ren A, Zhang L, Li Z, Hao L, Tian Y, Li Z. Awareness and use of folic acid and blood folate concentrations among pregnant women in northern China - An area with a high prevalence of neural tube defects. Reproductive Toxicology 2006; 22: 431-6.

26. Paudel P, Wing K, Silpakar SK. Awareness of periconceptional folic acid supplementation among Nepalese women of childbearing age: a crosssectional study. Preventive medicine. 2012. ISSN 0091-7435 DOI: https://doi.org/10.1016/j. ypmed. 2012.09.001

27. Canfield MA, Przybyla SM, Case AP, Ramadhani T, Suarez L, Dyer J. Folic acid awareness and supplementation among Texas women of child bearing age. Preventive Medicine. 2006; 43: 27-30.

28. March of Dimes. Folic acid and the prevention of birth defects: a national survey of pre-pregnancy awareness and behavior among women of childbearing age, 1995-2003. The Gallup Organization.

29. Centers for Disease Control and Prevention. Use of supplements containing folic acid among women of child bearing age - United States. MMWR. 2007; 57: 5-8. 
30. Bitzer J, von Stenglin A, Bannemerschult R. Women's awareness and periconceptional use of folic acid: data from a large European survey. International Journal of Women's Health. 2013; 5: 201-213.

31. Finer LB, Henshaw SK. Disparities in rates of unintended pregnancy in the United States. 1994 and 2001. Perspect Sex Reprod Health. 2006; 38(2): 90-96.

32. Callender ES, Rickard R, Miller L, Rinsky-Eng J. Knowledge and use of folic acid supplementation: a study of Colorado women whose pregnancies were affected by a fetal neural tube defect. Clin Invest Med 2001; 24: 124-8.

33. Al-Akhfash AA, Abdulla AM, Osman AM, Abdulgafar JI, Almesned AA. Maternal knowledge and use of folic acid among Saudi females. Saudi Med J 2013; 34 (11): 1173-78.

34. Riazi H, Bashirian S, Amini L. Awareness of Pregnant Women about Folic Acid Supplementation in Iran Journal of Family and Reproductive Health 2012; 6 (4): 159-63.

35. Tekkesin N, Taser F. Folic acid usage and awareness in pregnant women in Istanbul, Turkey. Hospital Administration. 2012; 1 (1): 9-14.

36. Vitale K, Mujkic A, Todorovic G, Tulchinsky TH. Is level of knowledge, attitude and use of folic acid among pregnant women in Croatia a call for public health action? Periodicum Biologorum 2009; 111(3): 329-35.

37. van Eijsden M, van der Wal M, Bonsel G. Folic acid knowledge and use in a multi-ethnic pregnancy cohort: the role of language proficiency. BJOG 2006; 113: 1446-51.

38. Meyer RE, Wall A, Morgan A, Devine J, Powers K. Knowledge and Use of Folic Acid Among North Carolina Women. MS NCMJ. 2002; 63(1): 18-22.

39. Benera A, Al Maadidb MGA, Al-Bastb DAE, AlMarric S. Maternal knowledge, attitude and practice on folic acid intake among Arabian Qatari women. Reproductive Toxicology 2006; 21: 21-25.

40. Wua DY, Bratb G, Millac G, Kima J. Knowledge and use of folic acid for prevention of birth defects amongst Honduran women Reproductive Toxicology. 2007; 23: 600-6.

41. Ren A, Zhang L, Li Z, Hao L, Tian Y, Li Z. Awareness and use of folic acid, and blood folate concentrations among pregnant women in northern China - An area with a high prevalence of neural tube defects. Reproductive Toxicology 2006: 22: 431-6.

42. Department of Census and Statistics, Ministry of National Policies and Economic Affairs, Sri Lanka (2012). Census of Population and Housing Sri Lanka 2012. 